\title{
Building Community
}

\author{
Natalia Nikolova \\ University of Technology Sydney \\ natalia.nikolova@uts.edu.au
}

Timothy Devinney

Australian Graduate School of Management

T.Devinney@agsm.edu.au 


\section{Building Community}

\section{Introduction}

That organizations cannot be viewed as uniform and stable cultures or entities but rather as communities of "loosely constituted overlapping circles of partialled participation" (Blau, 1996: 174) is not a new insight (e.g., Bechky, 2003; Bloor and Dawson, 1994; Dougherty, 1992). To make sense of this world of competing communities, one needs to understand why these subcultures exist, how they form, how they interact—cooperatively and competitively— and how they evolve. In what follows, we address these issues by providing an integrated view of the two theoretical approaches that have built on this thinking: communities of practice (CoP) and critical discourse analysis (CDA). The concept of interpretive communities (ICs), which we propose, builds upon important findings related to both CoP and CDA but overcomes their shortcomings and extends them onto a more general theoretical footing.

\section{Communities of practice, critical discourse analysis and interpretative communities}

CoP research claims that different communities exist because individuals are engaged in different activities or practices and knowledge transfer is possible only between individuals within a particular practice (e.g., Brown and Duguid, 1991, 2001; Gherardi and Nicolini, 2002; Lave and Wenger, 2002). Table 1 summarizes the main assumptions of the CoP view and offers a critical discussion of these assumptions. It shows that the CoP approach does not explain the role of human cognition and power for knowledge transfer and learning. In contrast, the concept of ICs emphasizes that cognition cannot be separated from practice and action and puts stronger emphasis on the connection between power and cognition.

\section{INSERT Table 1 ABOUT HERE}

According to CDA, organizations consist of multiple non-neutral and biased discourses that serve as “sites of power” that influence individuals’ interpretations (Mumby and Stohl, 
1991: 316). ${ }^{\text {i }}$ Supporters of CDA analyze how interpretations and perspectives have been "discursively constructed over time by groups in power aiming to skew social reality and institutionalized [knowledge] to their own advantage” (Heracleous, 2004: 186). Although CDA emphasizes the role of social practices and non-discursive elements for the creation and dissemination of discourses and power (e.g., Fairclough, 2005), the approach does not refer explicitly to the cognitive element of discourses. Texts are central to the analysis, not the brains that produce these texts. Thus, "where do the discourses, narratives, texts and words that are analyzed in organizational discourse come from?” (Marshak et al., 2000: 250) remains an open question.

Following van Dijk’s (1993: 251) proposition that cognition is the “missing link” between discourse and action, it is the contention put forward here that the concept of ICs is the missing theoretical link within CDA. Furthermore, our discussion outlines the concrete steps by which a particular discourse develops into a dominant position, a key missing component of CDA.

Beginning with the viewpoint that "a firm is composed of a group of people who all, in varying ways and to varying extents, interpret what they observe and take decisions according to their interpretation” (Loasby, 1983: 357), we argue that individuals with shared interpretive strategies and shared discourses-i.e., who employ a common frame of reference for interpreting their social settings—build an IC (Fish, 1980; Hymes, 1980). In order to get a more complete picture of how knowledge is acquired, created, processed and managed (Bechky, 2003) and who influences this process, we must understand the ongoing process of interaction between members of different communities. Furthermore, because knowledge transfer and learning are inherently political processes, we need to discuss the nature of power as well as the micro processes through which the power — what we call interpretive dominance- of a particular community is developed. Our goal is to present the reader with a multifaceted pic- 
ture of human cognition and to show important implications for our understanding of power and its role on learning.

\section{Origin and nature of interpretive communities}

If knowledge is a product of human cognition (Bunge, 1996; Maturana, 1980; Neisser, 1976), then what characterizes human cognition? Research in neurobiology shows that all cognitive processes are brain processes (e.g., Lakomski, 2004). Therefore, there are "no ideas in themselves but, instead, ideating brains” (Bunge, 1983: 23; also Lakomski, 2004; Maturana, 1980). At the same time, cognitive processes are in an intensive interaction with individuals' natural and social environment where concepts and symbols - the basis of thinking - are expressed in words that derive their meaning from the way they are used in specific language games or discourses, which themselves are located in distinct social settings (Koppl and Langlois, 2001). Therefore, cognition and discourse are mutually constituted in a process of continuous interaction (Heracleous, 2004). Consequently, context and the embedded existing discourses influence cognition significantly; in other words, cognition is a situated process. Tsoukas and Vladimirou (2003: 977-978) argue that this context can be interpreted as “a collectively generated and sustained domain of action” or “a language-mediated domain of sustained interactions", and "to engage in collective work is to engage in a discursive practice”. Thus, knowledge is created and transferred within socio-culturally constituted ICs or discursive practices through an ongoing process of interaction between individuals (Bechky, 2003). Cognition is both embodied, because people's physical composition determines their thinking, and embedded, because the specific context and situations people find themselves determine cognition (Lakomski, 2004).

The two major cognitive processes of perception and conception, together with action, are the sources of knowledge (Bunge, 1996: 76): "We get to know ideas by thinking of them, and concrete things by perceiving, conceiving, or manipulating them”. When perceiving some- 
thing, people construct a percept of it with sensations, memories, and expectations. They look for similarities and differences, and for patterns. This process, which is referred to as intuiting (Crossan et al., 1999) or sensemaking (Weick, 1979), involves the mapping of an event into one’s perceptual system (Bunge, 1983). The resulting cognitive maps are also called schemes. Perceptions themselves do not have a meaning. They can guide the actions of the individual, but they are difficult to share with others because they are non-verbal and subconscious (Crossan et al., 1999). Only through a process of interpreting do individuals assign a meaning to a particular perception (Neisser, 1976). Thus, meanings are the result of thinking processes. Schemes and their meanings are developed by individual experience. Therefore, "the same stimulus can evoke different or equivocal meaning for different people” (Crossan et al., 1999: 528). However, research has shown that individuals confronted with similar or the same physical and cultural environment can develop similar schemes and meanings (Neisser, 1976). In other words, the real world, which exists independently of our senses, enables individuals to develop some similar schemes and meanings. ${ }^{\text {ii }}$ Through the course of regular social interaction in the form of communication, participation, and problem-solving, individuals begin to favour one interpretation over others and their exchange of experiences leads to the emergence of shared schemes and meaning (Gray et al., 1985; Zelizer, 1993). Through this process of interaction, individuals with similar interpretive positions build specific worldviews and "form" a community. As individuals become aware of how their thoughts are guided by such frameworks they can start to choose between them: through their involvement in multiple communities and discourses individuals "produce a discursive space in which [they] can play one discourse against the other, draw on multiple discourses to create new forms of interdiscursivity, and otherwise move between and across multiple discourses” (Hardy and Phillips, 2004: 304). In this way, different ICs evolve, made up of those who share interpretive frames (Fish, 1980; Hymes, 1980) but who are themselves members of many 
evolving and potentially overlapping communities (e.g., Reihlen and Ringberg, 2004; Watson, 1982). Over time, individuals establish “conventions” or “dominant perspectives” as to how community members can recognize, create, experience, and talk about social events and ICs transform into “communities of memory” (Prahalad and Bettis, 1986; Zelizer, 1993). Therefore, ICs are instantiated both in the actions of their members and in their interpretations and interpretive schemes (Heracleous and Barrett, 2001: 758). They are cognitive communities that are a result of agents' actions and interactions.

An IC builds and expands through the shaping of individuals. As noted by Fish (1980), the thoughts of individuals have their source in some or other IC; thus, they are products of communities. At the same time, actors participating in these communities influence them through their ongoing interpretations and actions. For example, through the interaction with members of other ICs, individuals can introduce changes in a particular IC (Bloor and Dawson, 1994). Therefore, the shared meanings of communities are more or less often transformed (Brown and Duguid, 1991) and large-scale changes in ICs can be caused by largescale, more-or-less simultaneous frame switches by many independent actors (DiMaggio, 1997). Accordingly, ICs are fluid and evolving rather than unalterable "fixed systems of positions” (Clegg, 2001: 135; Carley, 1991). Some ICs can be quite durable whereas others are only short-lived; some are broad and expansive while others involve only a restricted number of members.

ICs as discursive practices are maintained at the group level but operate and are manifested through individuals' shared cognitive maps (Harris, 1989). Thus, the selection of environmental elements to be analyzed is likely to be affected by the shared schemes of an IC, and different schemes can lead to dramatically different analysis of the same event or topic (Fish, 1980). Accordingly, members of different ICs may have problems in understanding one another fully "if knowledge leaks in the direction of shared [meaning], it sticks where [meaning] 
is not shared” (Brown and Duguid, 2001: 207). Therefore, different communities are often characterized by distinct perspectives rather than by mutual understanding (Gherardi and Nicolini, 2002). Misunderstandings can be expressed in several ways. For example, when looking at the same phenomenon, communities may not only see different solutions to the same problem but may also address quite different problems. Thus, communities may have problems in understanding each other's language, “where each community maintains its own voice while listening to the voice of the Other, and where communication is both negotiated order and disorder” (Gherardi and Nicolini, 2002: 421). Furthermore, arguments that persuade one’s own community convincingly may have little or no weight with other communities (Boland and Tenkasi, 1995). Thus, ICs are characterized by different problem solving logics, which are a main reason for conflicts and communication problems in organizations (Carroll, 1998). Successful cooperation between members of different ICs requires the translation of the different perspectives so that some alignment of meanings is achieved; yet, translation is also a mechanism of power (Clegg, 1989, 2001).

\section{The power of interpretive communities}

Because members of ICs are embedded in multiple discourses, they can "play one discourse against another, draw on multiple discourses to create a new form of interdiscursivity, and otherwise move between and across multiple discourses” (Hardy and Phillips, 2004: 304). Therefore, interactions between ICs are characterized by harmonization, negotiation of meanings and the integration of interpretations as well as by contestations and struggles (Clegg, 1989; Gherardi and Nicolini, 2002), the ultimate goal of which is the establishment of interpretive dominance by one or a combination of communities (Callon, 1986; Meindl et al., 1994). Thus, when ICs interact, power rather than rationality is at work (Bettenhausen and Murnighan, 1985; Flyvbjerg, 1998). 
The concept of interpretive dominance examines "how the field of force in which power is arranged has been fixed, coupled and constituted in such a way that, intentionally or not, certain 'nodal points' of practice are privileged in this unstable and shifting terrain” (Clegg, 1989: 17). It is based on the assumption that the power relations amongst groups and actors are dependent on knowledge and institutionalized “truths” and discourses (e.g., Foucault, 1980). At the same time, actors influence existing power relations and institutionalized discourses through their ongoing interpretations and actions (e.g., Prahalad and Bettis, 1986).

\section{Power and interpretive dominance}

Interpretive dominance emerges during agents’ interactions as a result of negotiations and translations of meanings. It "operates through the offering and acceptance of reasons for acting in one way rather than another" (Scott, 2001: 13) and prevents agents from developing and legitimizing alternative interpretations. It is the result of rhetorical power; power, which is not predetermined by the possession or control of resources but is exercised through a set of “interpretive frames” (Mumby and Clair, 1997: 184). In it simplest form, rhetorical power rests upon a person's personality and attractiveness to others; i.e., in their charisma (Scott, 2001). However, rhetorical power is rarely the mere result of charisma. Rather, it is the result of cognitive and social processes, in which, “intrinsically appropriate reasons for action” are constructed and offered to others so that a particular course of action or decision comes to be seen as cognitively, morally, or emotionally appropriate (Scott, 2001). Such a persuasive influence does not depend on rational calculation but on arguments, appeals and reasons that cause individuals to believe that a particular decision or action is more appropriate than another (Scott, 2001). Rhetorical power can operate through cognitive symbols-ideas and representations that lead people to define situations in certain ways. It arises from the attribution of expertise or knowledge to the influencing agent and draws individuals into a particular interpretive framework (Scott, 2001; Somech and Drach-Zahavy, 2002; van Dijk, 1993). Rhe- 
torical power can also operate through the building of value commitments to particular ideas or conditions (Somech and Drach-Zahavy, 2002) and arises when individuals "defer to the views of those whom they regard as especially fitted to speak on behalf of these values" (Scott, 2001: 15). Therefore, rhetorical power does not imply the mere rhetorical superiority based on a person's charisma but also the power originating in cognitive symbols and arguments and in value commitments. ${ }^{\text {iii }}$

Existing practices and discourses often advantage particular groups of actors without those groups being clearly connected to the establishing or maintenance of discourses and practices (e.g., Lawrence et al., 2005). Thus, “some individuals, by virtue of their position in the discourse, will warrant a louder voice than others, while others may warrant no voice at all” (Hardy and Phillips, 1999: 4). Therefore, agents with some positional power, power that is embedded in existing relations and is based on resources, are better able to influence discourses and to develop interpretive dominance. At the same time, agents without positional power might be “silenced” (Brown and Coupland, 2005), with less chance to engage in discourses and meaning creation: "The most effective use of power occurs when those with power are able to get those without power to interpret the world from the former's point of view” (Mumby and Clair, 1997: 184). For example, agents who mediate between different ICs can use their position as a connecting point to enforce their preferred interpretation by translating other perspectives in a manner favorable to them. In the following, we illustrate the process through which interpretive dominance develops and discuss some of the characteristics of the single steps within this process.

\section{The emergence of interpretive dominance}

“The notion of interpretive dominance conceptualizes a belief system as an active arena, where interest groups [...] compete to impose their preferred psychological order onto nonbelievers” (Meindl et al., 1994: 291). Through the management of meanings and communica- 
tion, individuals and ICs can legitimate their interpretive positions and "institute a form of social control that removes the need to exercise control directly” (Phillips and Brown, 1993: 1551). We illustrate this process by referring to Callon's (1986) four “moments of translation”: problematization, interéssement, enrolment and mobilization.

\section{(1) Problematization}

Communication and coordinated action between members of different ICs are often problematic due to their different interpretations of the same issue, to misunderstandings, suspicion and anxiety of disclosure when interactions occur (Czarniawska and Mazza, 2003). Interaction between members of different ICs is successful only when they develop some shared schemes and begin to act and interpret using these (Bettenhausen and Murnighan, 1985), implying that some individuals must change their initial perspective (e.g., Mohammed and Ringseis, 2001). At the foundation of such a change is the attempt by some actors to manage meanings by introducing certain interpretations and establishing certain relations between interpretations (Benford and Snow, 2000; Gray et al., 1985). The goal is to associate the issue at hand with the preferred concept and perspective of these actors (Hardy et al., 2000). Thus, actors need to "engage" others into their interpretations and discourses.

The first step in this process involves the embedding of the suggested perspective in a larger discursive context so that it would have meaning for the individuals to whom it is directed (Hardy et al., 2000). This process has been called elsewhere "strategic fitting” or "recontextualization” (Benford and Snow, 2000; Fairclough, 2005) and encompasses the (intentional) tailoring and fitting of interpretations to the background and experiences of the other party (Benford and Snow, 2000). Next, actors draw the others' attention to certain aspects of their own experience, accenting and highlighting some issues or aspects as being more salient than others. In this way, they impose a pattern of meaning on otherwise ambiguous contexts (Gray et al., 2000). This process of meaning construction involves introducing certain con- 
cepts and interpretations, establishing certain relations between concepts, and imparting values as well as the use of a particular language (Gray et al., 1985; Lawrence et al., 2005). Although it is possible to use rhetoric based on inspirational appeals and emotional requests in order to arouse enthusiasm by appealing on the other's values and ideals, persuasions based on the use of logical arguments, factual evidence and existing discourses are the prevalent influence tactics at this stage (Yukl and Falbe, 1990). Thus, at this stage, cognitive persuasion prevails.

If successful, actors establish themselves as “obligatory passage points” (Callon, 1986)_agents with interpretive authority for others' problems (Zelizer, 1993). These “nodal points” are pivotal locations within discourses and when institutionalized, represent "fixed" knowledge domains that are regarded as normal practice. Thus, "problematization seeks to construct ‘hegemony’ by fixing [obligatory passage points]” (Clegg 1989: 204). ${ }^{\text {iv }}$ It is important to note that actors can engage in such problem formulation unintentionally: they will try to impose their interpretation of an issue because they are embedded in ICs and discourses that influence what they see and how they interpret what they see. However, other actors can also engage in translation and meaning creation by “counterframing”-by attempting to undermine or neutralize an actor's version and interpretive framework of the problem by creating a competing interpretation (Benford and Snow, 2000: 626). Such counterframing increases the chance for actors to break out of standard, established interpretations and views and to develop novel understandings. However, it is difficult because actors first have to undo all the already existent interpretations (Callon, 1991). In this case, the next three steps of the "translating” process become even more important.

(2) Interéssement

In the second step of the translation process actors try to lock others into the roles or identities they have defined for them by erecting an interpretation that serves to block or neu- 
tralize all potential competing interpretations. One of the goals of this step is to prevent actors from counterframing. Through rhetorical strategies, actors further influence the construction of cognitive maps on the part of others. Actors' rhetoric in this phase often utilizes emotional aspects by stressing that the suggested interpretation leads to a positive future to which the others are attracted and related to, implying that this particular interpretation will take them closer to a desired perspective and action (Ford and Ford, 1995). Thus, the use of symbolic and emotional appeals and, possibly, charisma is more prevalent than in the first phase. A successful “intéressement” results in the emergence of some "shared” understandings and confirms the validity of the suggested interpretation and the proposed role for the involved actors. However, an unsuccessful translation means that the individuals are no longer able to communicate, which will result in disalignment: actors "reconfigure themselves in separate spaces with no common measure” (Callon, 1991: 145).

(3) Enrolment

If “intéressement” is successful, a process of multilateral negotiations between actors takes place, coined “enrolment”, which aims at building alliances and coalitions with members of other ICs. The goal is to "enact" what started as a discourse- to transform the proposed interpretation into new ways of thinking, acting and interacting, into new ways of being and new identities, and, finally, in the materialization of the suggested interpretation, which can take form of new structures, rules, strategies, practices, etc. (Fairclough, 2005). Thus, in this phase, the interpretive schemes that actors started to share in the previous phase are enacted into concrete actions: the enrolled actors build coalitions and alliances and start to act as a cognitively coherent group in regard to the issue at hand.

(4) Mobilization of allies

This phase refers to methods and actions that ensure that interpretations, which were fixed in the previous phases, are widely dispersed through further discourses. It is important 
to ensure that the already "enrolled” actors do not betray or undercut the fixed interpretation so established. At this point, individual statements and practices are accumulated and they start to influence the context for future discourse activities, "as prevailing discourses are contested, displaced, transformed, modified or reinforced” (Hardy et al., 2000: 1236). At the same time, these existing discourses influence the process of dispersion of new interpretations, which makes it to an unpredictable process "since there are a number of contradictory ways in which knowledge can be consumed, some of which may be quite different from the intentions of the original producers” (Hardy and Phillips, 2004: 370). This is particularly the case when actors reinterpret the original interpretations and/or connect them in different ways to existing discourses.

\section{The role of rhetorical power in knowledge transfer and creation}

The rhetorical power that results in the interpretive dominance of particular ICs can have both constraining and enabling effects on learning processes. If the underlying interpretation is based on existing interpretations, rhetorical power is at work that further stabilizes and endorses an existing discourse through the "locking” of others into established discourses. Such rhetorical power prevents the creation of novel interpretations and knowledge. With a growing dispersion of existing practices the diversity of interpretations decreases as members of ICs are “disciplined” by existing practices and discourses (Lawrence et al., 2005).

However, rhetorical power does not always have negative effects. For example, the existence of established meanings and interpretive positions can enhance the process of exploitation of existing interpretations and knowledge (Lawrence et al., 2005). On the other hand, if several interpretive views of an issue are legitimate because each of the involved ICs sees different aspects of the issue and generates different solution paths, the involved individuals might not be able to agree on one. In other words, rational decision-making might not be possible. In order to overcome the ambiguity and uncertainty associated with pluralist interpreta- 
tions and to achieve collective action, it will be necessary for one IC to develop interpretive dominance (Lawrence et al., 2005).

If the generated interpretation is based in a new discourse, actors can use their rhetorical power to translate this novel interpretation into a general discourse for similar situations and, in this way, disturb existing discourses and institutionalize new ones. Through further discourses they can achieve a partial fixing of the novel interpretation. Its wide dispersion can lead to the development of new discourses and ICs that can shape other actors' understanding and interpretations.

From this perspective, rhetorical power provides "the energy that fuels" decision making in a pluralist environment (Lawrence et al., 2005: 188). Power in the knowledge transfer and creation process is not a dysfunctional aspect that needs to be remedied. Rather, it is an intrinsic part of this process that should be appreciated and understood and appropriately leveraged by members of ICs: "Without it, we face strategic paralysis because we lack a mechanism with which to make change happen” (Hardy, 1996: S3).

\section{Conclusion and directions for future research}

It is the relationship between knowledge, discourses and power and their role in the development of ICs that is at the heart of this chapter. Through our discussion, we bring cognition back into our understanding of power and learning. We view individuals as members of a number of different ICs and emphasize the unstable, evolving character of human cognition and the importance of the battle between the pluralities of interpretation, putting power in the centre of a discussion of knowledge transfer and learning. In our view, the power of an IC depends on the relevance and importance of its knowledge as well as on its on-going ability to enforce its perspective and persuade others of the superiority of its knowledge (Clegg, 1989, Fox, 2000; Sillence, 2000). 
Our approach is multidisciplinary integrating insights from evolutionary economics, organizational learning, cognitive psychology, and CDA and aiming at crossing the existing boundaries between different academic disciplines dealing with the same issue but emphasizing only single aspects. In our view, more interdisciplinary research is needed in order to understand and explain the complex nature of human interactions and actions. We see this evolving both theoretically and empirically. Theoretically, we need: (1) insightful interdisciplinary studies that account for the ways in which particular ICs emerge, develop and disappear; and (2) an understanding of the methods by which discursive change and interpretive dominance occur and reshape the power structures between ICs. Empirically, we need to engage in multilevel research that can simultaneously: (1) characterize ICs based upon the cognitive schema of the actors; (2) map the actual process of interpretative dominance development; and (3) reveal the interaction between ICs in the unstable environment of organizations, coalitions and alliances. Ultimately, studies of power and learning should not ignore the connection to cognition. Let us not forget that neither discourses nor power relations and structures would exist without individuals who create, disseminate, institutionalize and destroy them. 


\section{References}

Ackroyd, S. and Fleetwood, S. (2000) 'Realism in contemporary organisation and management studies’, in S. Ackroyd and S. Fleetwood (eds.), Realist Perspectives on Management and Organisations. London: Routledge, pp. 3-25.

Alfieri, A. (1994) ‘Practicing community’, Harvard Law Review 107 (7): 1747-1764.

Bechky, B. (2003) 'Sharing meaning across occupational communities: The transformation of understanding on a production floor', Organization Science 14 (3): 312-330.

Benford, R. and Snow, D. (2000) 'Framing processes and social movements: An overview and assessment', Annual Review of Sociology 26: 611-639.

Bettenhausen, K. and Murnighan, J. (1985) 'The emergence of norms in competitive decisionmaking groups’, Administrative Science Quarterly 30 (3): 350-372.

Blau, J. (1996) 'Organizations as overlapping jurisdictions: Restoring reason in organizational accounts’, Administrative Science Quarterly 41 (1): 172-179.

Boland, R. and Tenkasi, R. (1995) 'Perspective making and perspective taking in communities of knowing', Organization Science 6 (4): 350-372.

Bloor, G. and Dawson, P. (1994) 'Understanding professional culture in organizational context', Organization Studies 15 (2): 275-295.

Brown, A. and Coupland, C. (2005) 'Sounds of silence: Graduate trainees, hegemony and resistance’, Organization Studies 26 (7): 1049-1069.

Brown, J. and Duguid, P. (2001) ‘Knowledge and organization: A social-practice perspective', Organization Science 12 (2): 198-213. 
Brown, J. and Duguid, P. (1991) ‘Organizational learning and communities-of-practice: Toward a unified view of working, learning, and innovation', Organization Science 2 (1): 4057.

Brown, J., Collins, A. and Duguid, P. (1989) 'Situated cognition and the culture of learning', Educational Researcher 18 (1): 32-42.

Bunge, M. (1996) Finding Philosophy in Social Science. New Haven: Yale University Press.

Bunge, M. (1983) Treatise on Basic Philosophy Vol. 5. Epistemology and Methodology I: Exploring the World. Dordrecht: Kluwer.

Callon, M. (1986) 'Some elements of a sociology of translation: domestication of the scallops and the fishermen of St Brieuc Bay’, in J. Law (ed.), Power, Action and Belief. London: Routledge \& Kegan Paul, pp. 196-233.

Callon, M. (1991) ‘Techno-economic networks and irreversibility’, in J. Law (ed.), A Sociology of Monsters: Essays on Power, Technology and Domination. London: Routledge, pp. $131-164$.

Carley, K. (1991) ‘A theory of group stability’, American Sociological Review 56 (3): 331354.

Carroll, J. (1998) ‘Organizational learning activities in high-hazard industries: The logics underlying self-analysis’, Journal of Management Studies 35 (6): 699-717.

Clegg, S. (1989) Frameworks of Power. London: Sage Publications.

Clegg, S. (2001) 'Changing concepts of power, changing concepts of politics', Administrative Theory \& Practice 23 (2): 126-150.

Crossan, M., Lane, H. and White, R. (1999) 'An organizational learning framework: From intuition to institution', Academy of Management Review 24 (3): 522-537. 
Czarniawska, B. and Mazza, C. (2003) ‘Consulting as a liminal space’, Human Relations 56 (3): 267-290.

Dougherty, D. (1992) 'Interpretive barriers to successful product innovation in large firms', Organization Science 3 (2): 179-202.

Fairclough, N. (2005) 'Discourse analysis in organization studies: The case for critical realism’, Organization Studies 26 (6): 915-939.

Fairclough, N. (1992) Discourse and Social Change. Cambridge: Polity Press.

Fish, S. (1980) Is there a Text in this Class? The Authority of Interpretive Communities. Cambridge: Harvard University Press.

Flyvbjerg, B. (1998) Rationality and Power. Chicago: University of Chicago Press.

Ford, J. and Ford, L. (1995) 'The role of conversations in producing intentional change in organizations’, Academy of Management Review 20 (3): 541-570.

Fox, S. (2000) ‘Communities of practice, Foucault and actor-network theory’, Journal of Management Studies 37 (6): 853-867.

Foucault, M. (1980) Power/Knowledge: Selected Interviews and Other Writings, 1972-1977. New York: Pantheon Books.

Gherardi, S. and Nicolini, D. (2002) 'Learning in a constellation of interconnected practices: Canon or dissonance?’, Journal of Management Studies 39 (4): 419-436.

Gray, B., Bougon, M. and Donnellon, A. (1985) 'Organizations as constructions and destructions of meaning', Journal of Management 11 (2): 83-98.

Hardy, C. (1996) 'Understanding power: Bringing about strategic change’, British Journal of Management 7 (Special issue): S3-S16. 
Hardy, C., Lawrence, T. and Grant, D. (2005) 'Discourse and collaboration: The role of conversations and collective identity', Academy of Management Review 30 (1): 58-77.

Hardy, C., Palmer, I. and Phillips, N. (2000) ‘Discourse as a strategic resource’, Human Relations 53 (9): 1227-1248.

Hardy, C. and Phillips, N. (2004) ‘Discourse and power’, in D. Grant, C. Hardy, C. Oswick and L. Putnam (eds.), The SAGE Handbook of Organizational Discourse. Thousand Oaks: Sage, pp. 299-316.

Harris, S. (1989) 'A schema-based perspective on organizational culture’, Academy of Management Proceedings: 178-182.

Heracleous, L. (2004) 'Interpretivist approaches to organizational discourse’, in D. Grant, C. Hardy, C. Oswick and L. Putnam (eds.), The SAGE Handbook of Organizational Discourse. Thousand Oaks: Sage, pp. 175-192.

Heracleous, L. and Barrett, M. (2001)’, Organizational change as discourse: Communicative actions and deep structures in the context of information technology implementation', Academy of Management Journal 44 (4): 755-778.

Hymes, D. (1980) Language in Education: Ethnolinguistic Essays. Washington: Center for Applied Linguistics.

Koppl, R. and Langlois, R. (2001) ‘Organizations as language games’, Journal of Management and Governance 5 (3/4): 287-305.

Lakomski, G. (2004) 'On knowing in context’, British Journal of Management 15 (Special issue): S89-S95.

Lave, J. and Wenger, E. (2002) Situated Learning. Legitimate Peripheral Participation. Cambridge: Cambridge University Press. 
Lawrence, T., Mauws, M. and Dyck, B. (2005) 'The politics of organizational learning: Integrating power into the 4I framework', Academy of Management Review 30 (1): 180-191.

Leinhardt, G., Young, K. and Merriman, J. (1995) 'Integrating professional knowledge: The theory of practice and the practice of theory', Learning and Instruction 5 (4): 401-408.

Loasby, B. (1983) ‘Knowledge, learning and enterprise’, in J. Wiseman (ed.), Beyond Positive Economics? London: Macmillan, pp. 104-121.

Lorenz, E. (2001) 'Models of cognition, the contextualisation of knowledge and organisational theory', Journal of Management and Governance 5 (4): 307-330.

Marshak, R., Keenoy, T., Oswick, C. and Grant, D. (2000) ‘From outer words to inner worlds', The Journal of Applied Behavioral Science 36 (2): 245-258.

Marshall, N. and Rollinson, J. (2004) 'Maybe Bacon had a point: The politics of interpretation in collective sensemaking’, British Journal of Management 15 (Special issue): S71-S86.

Martin, J. and Siehl, C. (1983) 'Organizational culture and counterculture: An uneasy symbiosis’, Organizational Dynamics 12 (2): 52-64.

Maturana, H. (1980) ‘Biology of cognition’, in H. Maturana and F. Varela (eds.), Autopoesis and cognition. Dordrecht: D. Reidel, pp. 2-62.

Meindl, J., Stubbart, C. and Porac, J. (1994) ‘Cognition within and between organizations: Five key questions’, Organization Science 5 (3): 289-293.

Mohammed, S. and Ringseis, E. (2001) 'Cognitive diversity and consensus in group decision making: The role of inputs, processes, and outcomes', Organizational Behavior and Human Decision Processes 85 (2): 310-335.

Mumby, D. and Clair, R. (1997) 'Organizational discourse’, in T. A. van Dijk (ed.), Discourse as Structure and Process: Discourse Studies Vol. 2. London: Sage, pp. 181-205. 
Mumby, D. and Stohl, C. (1991) 'Power and discourse in organization studies: Absence and the dialectic of control', Discourse \& Society 2 (3): 313-332.

Neisser, U. (1976) Cognition and Reality. New York: Freeman.

Phillips, N. and Brown, J. (1993) 'Analyzing communication in and around organizations: A critical hermeneutic approach’, Academy of Management Journal 36 (6): 1547-1576.

Prahalad, C. and Bettis, R. (1986) 'The dominant logic: A new linkage between diversity and performance’, Strategic Management Journal 7 (6): 485-501.

Reed, M. (2004) ‘Getting real about organizational research’, in D. Grant, C. Hardy, C.

Oswick and L. Putnam (eds.), The SAGE Handbook of Organizational Discourse. Thousand Oaks: Sage, pp. 413-420.

Reihlen, M. and Ringberg, T. (2004) 'Exploring competing views on knowledge in management studies’, unpublished working paper, University of Wisconsin-Milwaukee.

Scott, J. (2001) Power. Oxford: Blackwell.

Sillince (2000), Rhetorical power, accountability and conflict in committees: An argumentation approach, Journal of Management Studies 37 (8): 1125-1156.

Tsoukas, H. and Vladimirou, E. (2001) 'What is organizational knowledge?', Journal of Management Studies 38 (7): 973-993.

Van Dijk, T. (1993) 'Principles of critical discourse analysis', Discourse \& Society 4 (2): 249-283.

Watson, T. (1982) ‘Group ideologies and organizational change’, Journal of Management Studies 19 (3): 259-275.

Weick, K. E. (1979) The Social Psychology of Organizing. Reading, Mass: Addison-Wesley. 
Yukl, G. and Falbe, C. (1990) 'Influence tactics and objectives in upward, downward and lateral influence attempts’, Journal of Applied Psychology 75 (2): 132-140.

Zelizer, B. (1993) 'Journalists as interpretive communities’, Critical Studies in Mass Communication 10: 219-237. 


\begin{tabular}{|c|c|c|}
\hline & Community of practice view & Shortcomings \\
\hline $\begin{array}{l}\text { Emergence of } \\
\text { communities: } \\
\text { Explanatory } \\
\text { factors }\end{array}$ & $\begin{array}{l}\text { Single factor: engagement within same } \\
\text { practice. }\end{array}$ & $\begin{array}{l}\text { Multiple factors: engagement within same practice, educational background, } \\
\text { social histories, site-specific or local knowledge. }\end{array}$ \\
\hline $\begin{array}{l}\text { Origin of } \\
\text { knowledge }\end{array}$ & $\begin{array}{l}\text { Practice: “A theory of situated cognition } \\
\text { suggests that activity and perception are } \\
\text { importantly and epistemologically prior- } \\
\text { at a nonconceptual level-to conceptual- } \\
\text { ization” (Brown et al., 1989: 40). }\end{array}$ & $\begin{array}{l}\text { Practice, i.e. action, together with perception and conception (Bunge, 1983). } \\
\text { CoP overemphasizes procedural and pragmatic knowledge and learning as a } \\
\text { process of participating and being able to perform the "practice”, ignoring the } \\
\text { importance of conceptual knowledge and the possibility of learning through } \\
\text { labeling, describing, analyzing and justifying; i.e., independently of partici- } \\
\text { pating in a particular practice (Leinhardt et al., 1995). Cognition and action } \\
\text { cannot be divorced from each other (Neisser, 1976). }\end{array}$ \\
\hline $\begin{array}{l}\text { Nature of } \\
\text { knowledge }\end{array}$ & $\begin{array}{l}\text { Knowledge exists independent of indi- } \\
\text { viduals; practices/objects as carriers of } \\
\text { knowledge. }\end{array}$ & $\begin{array}{l}\text { Individuals as carriers of knowledge; it is individuals' cognitive maps that } \\
\text { give meaning to practice, not vice versa (Bunge, 1983). “The patterns of relat- } \\
\text { ing and the cognitive activities encapsulated by the concept 'community of } \\
\text { practice' are possible in the first place because of the pattern recognition and } \\
\text { completion ability of real brains” (Lakomski, 2004: S93). }\end{array}$ \\
\hline $\begin{array}{l}\text { Types of } \\
\text { knowledge }\end{array}$ & $\begin{array}{l}\text { Emphasis on the local contextualization of } \\
\text { knowledge. }\end{array}$ & $\begin{array}{l}\text { The existence of generalized knowledge is rejected (Lorenz 2001); no inquiry } \\
\text { into the "mechanisms that might serve to transmit and diffuse knowledge be- } \\
\text { yond the confines of particular places and times" (Lorenz, 2001: 318). }\end{array}$ \\
\hline $\begin{array}{l}\text { Knowledge trans- } \\
\text { fer }\end{array}$ & $\begin{array}{l}\text { Engagement in similar activities (prac- } \\
\text { tices) enables knowledge transfer; knowl- } \\
\text { edge transfer outside of CoP not ex- } \\
\text { plained; individuals within the same } \\
\text { "practice” transmit and receive informa- } \\
\text { tion non-problematically. }\end{array}$ & $\begin{array}{l}\text { Collection of workplace narratives is not a sufficient mechanism to provide } \\
\text { evidence that CoP are successful in transferring knowledge. Rather, the } \\
\text { univocally interpretation of activities enables knowledge transfer (Lakomski, } \\
\text { 2004). }\end{array}$ \\
\hline Power & $\begin{array}{l}\text { Power depends on one’s position in the } \\
\text { CoP (Lave and Wenger, 2002). }\end{array}$ & $\begin{array}{l}\text { Power is located not only in the position of individuals but in social relations; } \\
\text { it is relational and diffused throughout society (Clegg, 1989, Scott, 2001). } \\
\text { Power issue within CoP approach ignored (e.g., Fox, 2000). }\end{array}$ \\
\hline
\end{tabular}

Table 1: Community of practice view: assumptions and shortcomings 
${ }^{i}$ This is the realist version of discourse analysis (Fairclough, 2005; Reed, 2004). According to the main, social constructivist version of discourse analysis, "organizations exist only in so far as their members create them through discourse” (Mumby and Clair, 1997: 181). In contrast, the realist version stresses that discursive practices are "constrained by the fact that they inevitably take place within a constituted material reality, with preconstituted objects and pre-constituted social subjects" (Fairclough, 1992: 60). It forbears from the view that a "collective identity [is] a linguistically produced object embodied in talk and other forms of text, rather than [] a set of beliefs [or interpretations] held in members' minds.” (Hardy et al., 2005: 62). Thus, the social constructivist form of discourse analysis is quite similar to the view of practices as carriers of knowledge as suggested by the CoP approach. We show that there is no such thing as convergent linguistic practices without the existence of some shared cognitive maps between the involved individuals.

${ }^{\text {ii }}$ Our approach is based on a realist ontology combined with an epistemological constructivism and epistemic relativism (also Acroyd and Fleetwood, 2005).

${ }^{\text {iii }}$ In practice, it is difficult to differentiate clearly between these subtypes of rhetorical power as they are closely interwoven (Scott, 2001).

${ }^{\text {iv }}$ Studies of IT consulting projects provide an example how consultants use managerial discourses to establish themselves, i.e. their knowledge and practices, as an "obligatory passage point" in the eyes of clients (Bloomfield and Best, 1992). Zelizer (1993) discusses this process in the case of journalists. 